\title{
Effect of Inspiratory Muscle Training on Quality of Life in Patients with Chronic Heart Failure
}

\author{
SALAH G. MOHAMED, M.Sc.; ZIENAB M. HELMY, Ph.D. and BASSANT H. AL-REFAAY, Ph.D. \\ The Department of Physical Therapy for Cardiovascular/Respiratory Disorder \& Geriatrics, Faculty of Physical Therapy, \\ Cairo University
}

\begin{abstract}
Background: The present study was applied on thirty patients with chronic heart failure to detect the efficacy of inspiratory muscle training on their quality of life.

Aim of Study: The present study was conducted to investigate the efficacy of inspiratory muscle training on quality of life in patients with chronic heart failure.

Material and Methods: Thirty chronic heart failure patients were included in this study, their ages ranged from 50 to 60 years, they had Body mass index (BMI) ranged from 25-29.9 $\left(\mathrm{kg} / \mathrm{m}^{2}\right)$, they were selected from Tajora Heart Hospital in Libya and at the out-patient clinic, Faculty of Physical Therapy, Cairo University. They were divided randomly into two equal groups (A and B). Group (A) received selected physical therapy program about half an hour, while Group (B) received same physical therapy program that applied in the group (A) in addition to inspiratory muscle training using Inspiratory Muscle Trainer (IMT). The variables that used on this study, included Quality of Life Questionnaire (QLQ), dyspnea scale and ejection fraction, were assessed before and after treatment program in both groups. Both groups received treatment program 3 times/week for twelve weeks.
\end{abstract}

Results: The results revealed significant improvement of all measured variables in two groups after twelve successive weeks, also revealed significant difference when compared the two groups after treatment in favor of the group B.

Conclusion: Within the limitation of the present study it could be concluded that: The IMT results in marked improvement in Quality of Life Questionnaire (QLQ), dyspnea scale and ejection fraction.

Key Words: Patients with chronic heart failure - Inspiratory muscle trainer - Quality of life.

\section{Introduction}

HEART failure is a chronic disease characterized by the inability of the heart to pump an adequate

Correspondence to: Dr. Salah G. Mohamed, The Department of Physical Therapy for Cardiovascular/Respiratory Disorder \& Geriatrics, Faculty of Physical Therapy,

Cairo University amount of blood to achieve the demand of the different organ systems and/or doing so at increased filling pressures. It is a serious condition representing the end stage of a myriad of other cardiac diseases without a curative treatment. Once diagnosed, medication is required for the rest of the patient's life to improve their life quality and survival [1]

Most patients with Chronic Heart Failure (CHF) are limited in their physical activity by fatigue and dyspnea, and it has been suggested that respiratory muscle weakness and deconditioning may be involved in the increased work of breathing during hyperpnea. Some of these patients show reduced maximal inspiratory pressure (PImax) and endurance of inspiratory muscles, which are currently recognized as additional factors implicated in the limited exercise response and quality of life, as well as in their poor prognosis [2].

Respiratory muscle weakness is the primary reason for the inability of respiratory muscles to meet the increased demands of breathing during physical activity, with important secondary consequences [3]. These include dyspnoea, exercise intolerance, sleep disturbances, speech and swallowing problems, as well as musculoskeletal and posture problems due to the loss of the stabilising function of the respiratory musculature [4].

Training frequency is typically once or twice per day, on at least 5 days per week. In chronic disease such as COPD, long-term RMT will be most beneficial, as improvements are still observed after 12 months of training [5]. Conditions such as heart failure require lower training intensities (at around $30-60 \%$ of maximal inspiratory pressure) at the same frequency to optimise training benefit 
with consideration given to patient's baseline parameters and extent of respiratory muscle weakness. The RMT protocol should therefore be patient tailored, and integrated into the patient's lifestyle for long lasting benefits [6]

RMT during which resistance is added to inspiratory flow will specifically train inspiratory muscles, especially the diaphragm, which generates negative intrathoracic pressure and enlarges the thoracic cavity during inspiration. Other inspiratory muscles include the external intercostals muscles, essential for rib cage flexibility, while scalene and sternocleidomastoid muscles lift the rib cage during inspiration [7].

The IMT may decrease work of breathing, metabolic costs of breathing and perception of nervous system's perception of inspiratory output, so that dyspnea and exercise capacity would be improved. Peripheral muscle weakness also results in exercise intolerance and a study suggested that blood flow is distributed from respiratory to locomotor muscles during unloaded breathing. IMT may increase blood flow to peripheral muscles so that, peripheral muscle strength and also exercise capacity should be improved [8] .

\section{Material and Methods}

The study was conducted at Tajora Heart Hospital in Libya and at the out-patient clinic, Faculty of Physical Therapy, Cairo University at the period between March 2017 and April 2018, patient refered by physician.

Thirty chronic heart failure patients with left ventricular ejection fraction range from $30 \%$ to $45 \%$ and their New York Heart Association (NYHA) classes II and III were conducted in this study, their ages ranged from 50 to 60 years, they had Body Mass Index (BMI) ranged from 25-29.9 $\left(\mathrm{kg} / \mathrm{m}^{2}\right)$, they were divided randomly into two equal groups (A and $\mathrm{B}$ ).

Group (A) (control group): Received selected physical therapy program about half an hour 3 times/week for twelve weeks.

Group (B) (study group): Received same physical therapy program that applied in the group (A) in addition to inspiratory muscle training using inspiratory muscle trainer 3 times/week for twelve weeks.

The participated patients were selected according to the following inclusion criteria: Their ages would be ranged from 50-60 years, Body Mass
Index (BMI) would be ranged from $25-29.9 \mathrm{Kg} / \mathrm{m}^{2}$, all patients would be diagnosed as having chronic heart failure with left ventricular ejection fraction range from $30 \%$ to $45 \%$ and their NYHA classes II and III, inspiratory muscle weakness with maximal inspiratory pressure $30-50 \%$ and all patients would be clinically and medically stable as they would be on standard cardiac medications all over the study (diuretics, Angiotensin Converting Enzyme (ACE) inhibitors, and glycosides etc ...

Those patients who were excluded from study: Patients with chronic lung disorders, anemia or severe hypoxia, history of myocardial infarction or pulmonary edema six months before study, presence of uncontrolled hypertension or diabetes mellitus, patients with left ventricular ejection fraction less than $30 \%$ and any other disorder may affect the result (musculoskeletal neuromuscular).

\section{II- Material and methods:}

\section{A- Evaluation instrumentations:}

1- Quality of Life Questionnaire (QLQ): It would be assessed with the Minnesota Living with Heart Failure Questionnaire. It was assessed with the Minnesota Living with Heart Failure Questionnaire. It consisted of questions for patients to know how much their heart failure (heart condition) affect their life during the past month (4 weeks). After each question, circle the $0,1,2,3,4$ or 5 to show how much their life was affected. If a question was not applicable to patient, circled the 0 was circle after that question.

2- Dyspnea scale: Comprises five statements that describe almost the entire range of respiratory disability from none (Grade 1) to almost complete incapacity (Grade 5). It comprises five statements that describe almost the entire range of respiratory disability from none (Grade 1) to almost complete incapacity (Grade 5).

- Grade (1): No troubled by breathlessness except on strenuous exercise.

- Grade (2): Short of breath when hurrying on the level or walking up a slight hill.

- Grade (3): Walk slower than most people on the level, stops after a mile or so, or stops after 15 minutes walking at own pace.

- Grade (4): Stop for breath after walking about 100 yards or after a few minutes on level ground.

- Grade (5): Too breathless to leave the house, or breathless when undressing.

3- Echocardiography (Us 9500): For measuring left ventricular ejection fraction. It's a type of 
ultrasound scan, which means a small probe is used to send out high-frequency sound waves that create echoes when they bounce off different parts of the body. The patient should have a supine lying position, turning off his/her clothes to be in a relaxed position. The therapist put the head of Eco in the side of the heart for measuring the left ventricular ejection fraction.

$$
\begin{aligned}
& \text { 4- PImax predicted. It was calculated as the } \\
& \text { following: } \\
& \text { Men: MIP }=126-1.028 \mathrm{X} \text { age }+0.343 \mathrm{X} \text { wt }(\mathrm{kg}) . \\
& \text { Women: } \mathrm{MIP}=171-0.694 \mathrm{X} \text { age }+0.861 \mathrm{X} \mathrm{wt} \\
& \quad(\mathrm{kg})-0.743 \mathrm{X} \mathrm{ht}(\mathrm{cm}) .
\end{aligned}
$$

\section{B- Treatment measurement:}

For control group (group A): This group received selected physical therapy program about half an hour, three times per week for twelve weeks. The selected breathing physical therapy program was applied in form of the following:

1- Diaphragmatic breathing with static abdominal contraction exercise.

\section{2- Diaphragmatic breathing exercise.}

3- Segmental breathing exercise: It is important to emphasize expansion of the localized area of the lung while keeping other area quit. There are three types of the segmental breathing exercise include: Lateral costal expansion, posterior basal expansion, apical expansion exercise and pursed lip breathing exercise.

For study group (group B): This group received the same physical therapy program that applied in the group $(\mathrm{A})$ in addition to inspiratory muscle training using inspiratory muscle trainer, three times per week for twelve weeks.

Inspiratory muscle trainer: (Model 64485, Threshold IMT, US) Calibrated, Spring-Loaded Valve, adjustable pressure, $7-41 \mathrm{~cm} \mathrm{H} 2 \mathrm{O}$. The Trainer is designed to strengthen respiratory muscles through the use of resistance during the inspiratory effort. Features include three different colors coded resistors for setting the resistance level, port for monitoring pressures or delivering oxygen, and noseclip [2]

Inspiratory muscle training: Patients received IMT for 30min three times per week for twelve weeks using the Threshold Inspiratory Muscle Training device. For the IMT group, inspiratory load was set at $30 \%$ of maximal static inspiratory pressure, and monthly training loads were adjusted to maintain $30 \%$ of the PImax [2].

\section{Results}

The results of Quality of Life Questionnaire (QLQ), dyspnea scale and ejection fraction that were be assessed before treatment (pre-treatment), after twelve weeks of treatment application (posttreatment) for each chronic heart failure patients with left ventricular ejection fraction in this study in which revealed significant improvement in all variables.

\section{1- Quality of Life Questionnaire (QLQ):}

A- As presented in (Table 1) and demonstrated in Fig. (1), within group comparison revealed significant difference between the pre and postmedian values in groups A and B.

B- As presented in (Table 2), there was significant difference when comparing between postmedian values of groups A and B in favor of group B.

\section{2- Dyspnea scale:}

A- As presented in (Table 3) and demonstrated in Fig. (2), within group comparison revealed significant difference between the pre and postmedian values in groups A and B.

B- As presented in (Table 4), there was significant difference when comparing between postmedian values of groups A and B in favor of group B.

\section{3- Ejection fraction:}

A- As presented in (Table 5) and demonstrated in Fig. (3), within group comparison revealed significant difference between the pre and postmean values in groups A and B.

B- As presented in (Table 6), there was significant difference when comparing between postmean values of groups A and B in favor of group B.

Table (1): Comparing the median values of quality of life questionnaire (QLQ) among the two groups.

\begin{tabular}{lccccc}
\hline \multirow{2}{*}{$\begin{array}{l}\text { Quality of life } \\
\text { questionnaire }\end{array}$} & \multicolumn{2}{c}{ Group (A) } & & \multicolumn{2}{c}{ Group (B) } \\
\cline { 2 - 3 } \cline { 5 - 6 } & $\begin{array}{c}\text { Pre- } \\
\text { treatment }\end{array}$ & $\begin{array}{c}\text { Post- } \\
\text { treatment }\end{array}$ & & $\begin{array}{c}\text { Pre- } \\
\text { treatment }\end{array}$ & $\begin{array}{c}\text { Post- } \\
\text { treatment }\end{array}$ \\
\hline Median & 51 & 44 & & 50 & 39 \\
MD & 7 & & & 11 & \\
\% of improvement & $13.72 \%$ & & $22 \%$ \\
Z-value & 16.91 & & 25.6 \\
$p$-value & 0.000 & & \multicolumn{2}{c}{0.000} \\
Level of significant & $\mathrm{S}$ & & \multicolumn{2}{c}{$\mathrm{S}$} \\
\hline
\end{tabular}


Table (2): Comparing between post-treatment median values of Quality of Life Questionnaire (QLQ) between the two groups.

\begin{tabular}{|c|c|c|}
\hline \multirow{2}{*}{$\begin{array}{l}\text { Two } \\
\text { groups }\end{array}$} & \multicolumn{2}{|c|}{$\begin{array}{c}\text { Quality of life questionnaire (QLQ) } \\
\text { Post-treatment }\end{array}$} \\
\hline & Group (A) & Group (B) \\
\hline Median & 44 & 39 \\
\hline MD & \multicolumn{2}{|c|}{5} \\
\hline$t$-value & \multicolumn{2}{|c|}{296.5} \\
\hline$p$-value & \multicolumn{2}{|c|}{0.005} \\
\hline Level of significant & \multicolumn{2}{|c|}{$\mathrm{S}$} \\
\hline
\end{tabular}

Table (3): Comparing the median values of dyspnea scale among the two groups.

\begin{tabular}{lcccc}
\hline \multirow{2}{*}{ Dyspnea scale } & \multicolumn{2}{c}{ Group (A) } & \multicolumn{2}{c}{ Group (B) } \\
\cline { 2 - 5 } & $\begin{array}{c}\text { Pre- } \\
\text { treatment }\end{array}$ & $\begin{array}{c}\text { Post- } \\
\text { treatment }\end{array}$ & $\begin{array}{c}\text { Pre- } \\
\text { treatment }\end{array}$ & $\begin{array}{c}\text { Post- } \\
\text { treatment }\end{array}$ \\
\hline Median & 4 & 2.5 & 3.5 & 1.5 \\
MD & 1.5 & 2 & $57.14 \%$ \\
\% of improvement & $37.5 \%$ & \multicolumn{2}{c}{9.37} \\
Z-value & 10.58 & \multicolumn{2}{c}{0.000} \\
$p$-value & 0.000 & $\mathrm{~S}$ \\
Level of significant & $\mathrm{S}$ & \multicolumn{2}{c}{} \\
\hline
\end{tabular}

Table (4): Comparing between post- treatment median values of dyspnea scale between the two groups.

\begin{tabular}{|c|c|c|}
\hline \multirow{2}{*}{$\begin{array}{l}\text { Two } \\
\text { groups }\end{array}$} & \multicolumn{2}{|c|}{$\begin{array}{l}\text { Dyspnea scale } \\
\text { Post-treatment }\end{array}$} \\
\hline & Group (A) & Group (B) \\
\hline Median & 2.5 & 1.5 \\
\hline MD & \multicolumn{2}{|c|}{1} \\
\hline$t$-value & \multicolumn{2}{|c|}{292.5} \\
\hline$p$-value & \multicolumn{2}{|c|}{0.004} \\
\hline Level of significant & \multicolumn{2}{|c|}{$\mathrm{S}$} \\
\hline
\end{tabular}

Table (5): Comparing the mean values of ejection fraction among the two groups.

\begin{tabular}{|c|c|c|c|c|}
\hline \multirow[b]{2}{*}{ Ejection fraction } & \multicolumn{2}{|c|}{ Group (A) } & \multicolumn{2}{|c|}{ Group (B) } \\
\hline & $\begin{array}{c}\text { Pre- } \\
\text { treatment }\end{array}$ & $\begin{array}{c}\text { Post- } \\
\text { treatment }\end{array}$ & $\begin{array}{c}\text { Pre- } \\
\text { treatment }\end{array}$ & $\begin{array}{c}\text { Post- } \\
\text { treatment }\end{array}$ \\
\hline Median & \multicolumn{2}{|c|}{$33.22 \pm 1.8636 .69 \pm 1.78$} & \multicolumn{2}{|c|}{$33.09 \pm 2.1738 .81 \pm 1.5$} \\
\hline MD & \multicolumn{2}{|c|}{3.47} & \multicolumn{2}{|c|}{5.72} \\
\hline$\%$ of improvement & \multicolumn{2}{|c|}{$10.44 \%$} & \multicolumn{2}{|c|}{$17.28 \%$} \\
\hline$t$-value & \multicolumn{2}{|c|}{12.83} & \multicolumn{2}{|c|}{19.55} \\
\hline$p$-value & \multicolumn{2}{|c|}{0.000} & \multicolumn{2}{|c|}{0.000} \\
\hline Level of significant & \multicolumn{2}{|l|}{$S$} & \multicolumn{2}{|l|}{ S } \\
\hline
\end{tabular}

Table (6): Comparing between post-treatment mean values of ejection fraction between the two groups.

\begin{tabular}{|c|c|c|}
\hline \multirow{2}{*}{ Two groups } & \multicolumn{2}{|c|}{$\begin{array}{c}\text { Ejection fraction } \\
\text { Post-treatment }\end{array}$} \\
\hline & Group (A) & Group (B) \\
\hline Mean $\pm \mathrm{SD}$ & $36.69 \pm 1.78$ & $38.81 \pm 1.5$ \\
\hline MD & \multicolumn{2}{|c|}{2.12} \\
\hline$t$-value & \multicolumn{2}{|c|}{3.52} \\
\hline$p$-value & \multicolumn{2}{|c|}{0.002} \\
\hline Level of significant & \multicolumn{2}{|c|}{ S } \\
\hline
\end{tabular}

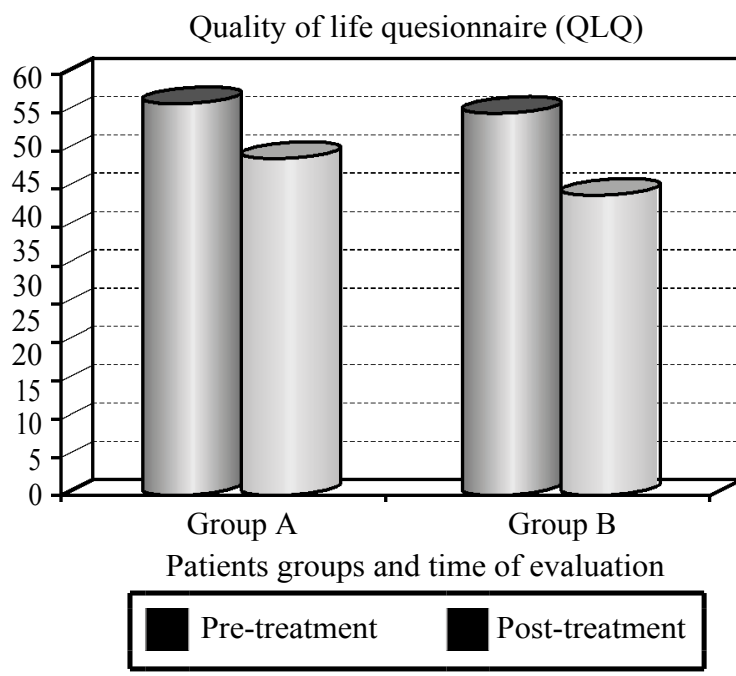

Fig. (1): Pre and post-treatment median values of Quality of Life Questionnaire (QLQ) among the two groups.

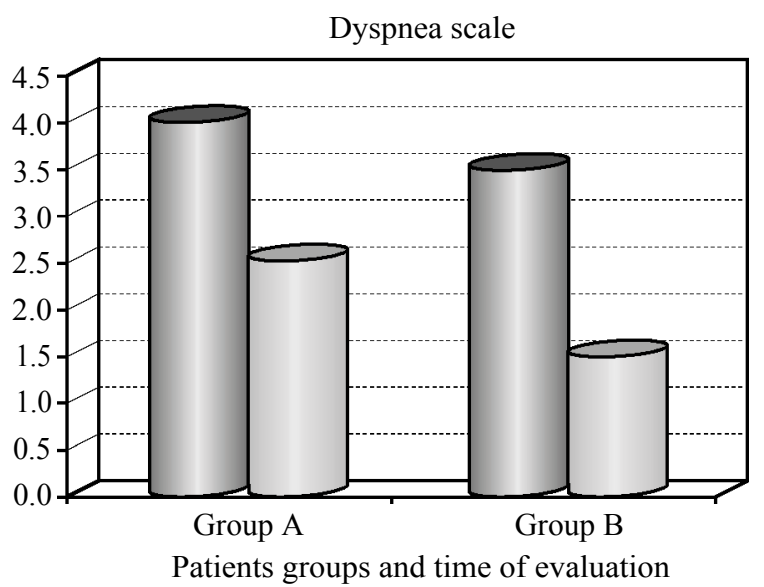

Patients groups and time of evaluation

Pre-treatment Post-treatment

Fig. (2): Pre and post-treatment median values of dyspnea scale among the two groups.

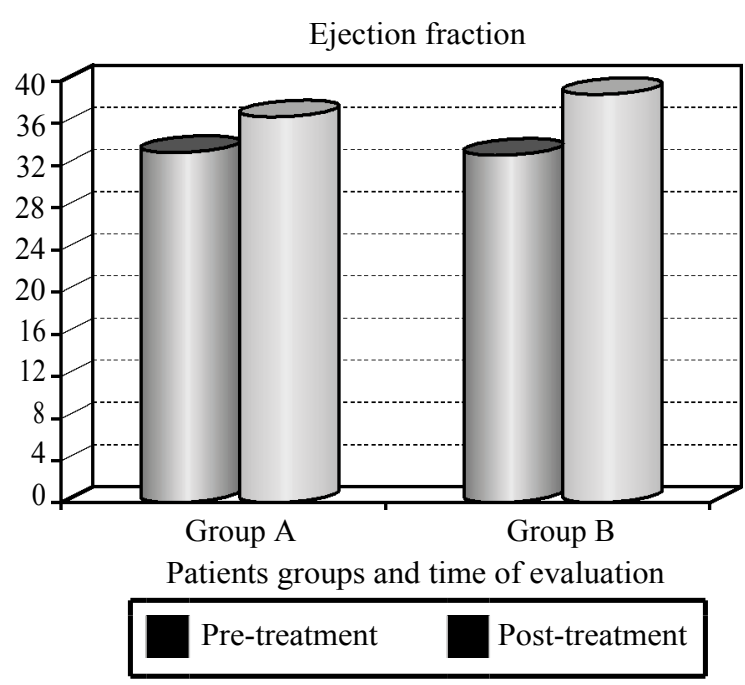

Fig. (3): Pre and post-treatment mean values of ejection fraction among the two groups. 


\section{Discussion}

The present work was essentially planned to investigate the efficacy of inspiratory muscle training on quality of life in patients with chronic heart failureas measured by decrease in left ejection fraction.

The current study was applied due to $\mathrm{CHF}$ patients are limited in their physical activty by fatigue and dyspnea, and respiratory muscle weakness deconditioning may be involved in the increased work of breath during hyperpnea. Some of these patients show reduced maximal inspiratory pressure (PImax) and endurance of inspiratory muscles, which are currently recognized as additional factors implicated in the limited exercises response and quality of life, as well as in their poor prognosis [9].

Also, the selection of the patients with CHF in the present study was supported by [10] who said that, patients with CHF were characterized by impaired lung function compared to healthy individuals. Some authors attribute these findings to respiratory muscle weakness, lung fluid imbalance, and exaggerated neurohumoral activity diaphragm, altering its normal return to its relaxed position.

Selection of the age of the participated patients in this study was ranging from 50 to 60 years to coincide with the findings of [1] who revealed that, African Americans (AAs) between the age of 45 and 65 years have a $70 \%$ higher rate of $\mathrm{HF}$, with mortality rates of 2.5 times more than the caucasian population. The current estimated number of AAs with heart failure is about 700,000 with an expected increase to 900,000 in 2010.

Choosing quality of life questionnaire, Dyspnea scale and left ventricular ejection fraction were accepted with [11] who said that, measurement of left ventricular performance is a critical step in the evaluation and management of patients with suspected or clinically apparent heart failure. Most patients with HF have an ejection fraction less than $40 \%$. However, patients with an ejection fraction greater than $40 \%$ can still have HF because of valvular disease or left ventricular diastolic dysfunction.

It is considered to be an important point for those patients's life and therefore could be of importance in view of clinical issues as revealed by [12] who reported that, the reported benefits of regular therapeutic exercise include improved exercise tolerance and at least partial relief from symptoms and muscle weakness. However, the impact of exercise therapy on the patient's perception of quality of life is not well established.

The selection of previous parameters comes in agreement with [11] who emphasized that, because the ejection fraction is used to establish a diagnosis of left ventricular systolic dysfunction, clinicians have extrapolated from this that the degree of left ventricular dysfunction will define the clinical course and prognosis. Although the ejection fraction does have prognostic value, there are distinct limitations to placing a strong reliance on the ejection fraction whether for establishing a prognosis or guiding therapy.

The previous results are agreed with [13] who mentioned that, exercise training has no effect on central hemodynamics (pulmonary artery pressure, pulmonary wedge pressure), but it does increase cardiac output at submaximal and peak exercise compared to baseline, and with exercise is associated with a lower double product (the value arrived at by multiplying the heart rate by the blood pressure).

Also, the finding results of this study revealed that IMT intervention improves quality of life, particularly in patients with inspiratory muscle weakness. Some benefit from IMT may be accounted for attenuation of the inspiratory muscle metabolic reflex. Moreover, IMT results in improved cardiovascular responses to exercise and to those obtained with standard aerobic training [8]

Comparing the pre and post-treatment results in quality of life questionnaire of the patients of the two groups (A and B) are agreed with [12] who proved that, physical activity such as physical functioning, role limitation caused by physical problems and social competence were markedly improved. The exercise training program was successful in increasing physical performance. This is expressed by the significant increase in maximal oxygen uptake.

The present results comes in agreement with [14] who said that, IMT program results in a significant and clinically important improvement in quality of life in patients with severe stable CHF. Further investigation should be directed towards the impact of the different components of the rehabilitation process upon quality of life improvement in patients with severe chronic heart failure.

Comparing the post-treatment values for the two groups revealed significant differences in favor of group (B) comes in agreement with [2] who stated that, improvement in inspiratory muscle 
strength and endurance, which results in clinically relevant increments of improvement in submaximal and maximal functional capacity, as well as in quality of life in CHF patients with inspiratory muscle weakness.

The present results are accepted with [15] who said that, selective inspiratory muscle training is beneficial for patients with CHF. The benefits include increased inspiratory muscle strength, increased inspiratory endurance, improved exercise capacity, reduced dyspnea, and probably improved quality of life. The effect sizes were considered "large" for improvements of respiratory muscle strength, functional exercise capacity, and reduction of dyspnea. It is recommended that patients with $\mathrm{CHF}$ should be screened for inspiratory muscle weakness routinely.

Comparing the pre and post-treatment results in Dyspnea scale of the patients of the two groups (A and B) are accepted with [16] who mentioned that, increasing respiratory muscle strength, inspiratory muscle training improved functional capacity, exercise capacity, dyspnoea and quality of life.

Comparing the post-treatment values for the two groups revealed significant differences in favor of group (B) are agreed with [17] who conducted that, the effects of IMT on dyspnea during daily living, depression, muscle strength and functional balance. Increase in inspiratory muscle strength resulted in clinically important decrease in dyspnea perception during daily living and depression; increase muscle strength and functional balance, which are very important outcomes, affecting exercise capacity and quality of life in patients with HF.

Comparing the pre and post-treatment results in left ventricular ejection fraction of the patients of the two groups (A and B) comes in contrast with [18] who stated that, the ejection fraction may also be a poor predictor of functional status and prognosis. In patients with HF, there is no relationship between the left ventricular ejection fraction and exercise capacity. Further, there is no relationship between the resting cardiac output and calf blood flow in patients with CHF.

Comparing the post-treatment values for the two groups revealed significant differences in favor of group (B) are agreed with [19] who proved that, IMT is a technique that target the muscles of inspiration-namely the diaphragm and accessory inspiratory muscles with the aim of increasing inspiratory muscle strength and endurance. Inspiratory muscles respond to training in the same way as other skeletal muscles in regard to the principles of overload, specificity and reversibility.

\section{References}

1- NASIF M. and ALAHMAD A.: "Congestive heart failure and puplic health". Thesis doctoral degree, 1-14, 2014.

2- DALL'AGO P., CHIAPPA G., GUTHS H., STEIN R. and RIBEIRO J.: "Inspiratory muscle training in patients with heart failure and inspiratory muscle weakness: A randomized trial". J. Am. Coll. Cardiol., 47 (4): 757-63, 2006.

3- LAGHI F. and TOBIN M.: "Disorders of the respiratory muscles". Am. J. Respir. Crit. Care. Med., 168: 10-48, 2003.

4- BOTT J., BLUMENTHAL S. and BUXTON M.: "Guidelines for the physiotherapy management of the adult, medical, spontaneously breathing patient". Thorax, 64: 148-52, 2009.

5- BECKERMAN M., MAGADLE R. and WEINER M. "The effects of 1 year of specific inspiratory muscle training in patients with COPD". Chest, 128: 3177-82, 2005.

6- MELLO P.R., GUERRA G.M. and BORILE S.M.: "Inspiratory muscle training reduces sympathetic nervous activity and improves inspiratory muscle weakness and quality of life in patients with chronic heart failure", 32: 255-61, 2012.

7- FERREIRA J.B., PLENTZ R.D. and STEIN C.R.: "Inspiratory muscle training reduces blood pressure and sympathetic activity in hypertensive patients: A randomized controlled trial". Int. J. Cardiol., 166: 61-7, 2013.

8- RIBEIRO J.P., CHIAPPA G.R., NEDER A.M. and FRANKENSTEIN L.N.: "Respiratory muscle function and exercise intolerance in heart failure". Curr. Heart Fail. Resp., 6 (2): 95-101. J. Cardiopulm. Rehabil. Prev., 2009.

9- COATS A.J.S.: "Why ventilator in efficiency matters in chronic heart failure". Eur. Heart J., 26 (5): 426-7, 2005.

10- BRANDAO D.C., LAGE S.M., BRITTO R.R., PARREIRA V.F., De OLIVEIRA W.A.,, MARTINS S.M., ALIVERTI A.M., CARVALHO L.D., JUNIOR J.F. and LUCIANA A.B.: "Chest wall regional volume in heart failure patients during inspiratory loaded breathing". Respiratory Physiology \& Neurobiology, 180: 269-74, 2012.

11-ROGERS F.J.: "The muscle hypothesis: A model of chronic heart failure appropriate for osteopathic medicine". J.A.O.A., 101 (10): 576-83, 2011.

12- QUITTAN M., STURM B., WIESINGER G., PACHER R. and FIALKA-MOSER V.: "Quality of life in patients with chronic heart failure: A randomized controlled trial of changes induced by a regular exercise program". Scand J. Rehab Med., 31: 223 - 228, 2009.

13-Wielenga R. P., Coats A. J., Mosterd W. L. and HUISVELD I.A.: "The role of exercise training in chronic heart failure." Heart, 78: 431-6, 2007.

14- METRA M., TEERLINK J., FELKER G., GREENBERG B., FILIPATOS G., PONIKOWSKI P., TIECHMAN S., 
UNEMORI E., VOORS A., WEATHERLEY B. and COTTER G.: " Dyspnea and wosening heart failure in patients with acute heart failure: Results from the Pre-Relax-Ahf study". Eur. J. Heart Fail., 12: 1130-9, 2010.

15- LIN S., McELFRESH J., HALL B., BLOOM R. and FARRELL K.: "Inspiratory Muscle Training in Patients with Heart Failure: A Systematic Review". Cardiopulmonary Physical Therapy Journal, 23 (3): 29-36, 2012.

16- De MEDEIROS A.C., FUZARI H.K., RATTES C.M., BRANDÃO D. C. and De MELO MARINHO. P.E.: "Inspiratory muscle training improves respiratory muscle strength, functional capacity and quality of life in patients with chronic kidney disease: A systematic review". Journal of Physiotherapy, 63: 76-83, 2017.
17- BOSNAK-GUCLU M., ARIKAN H., SAVCI S., INALINCE D., TULUMEN E., AYTEMIR K. and TOKGOZOGLU L.: "Effects of inspiratory muscle training in patients with heart failure". Respiratory Medicine, 105: 1671-81, 2011.

18- KETEYIAN S.J., BRAWNER C.A. and SCHAIRER J.R.: "Exercise testing and training of patients with heart failure due to left ventricular systolic dysfunction". J. Cardiopulm. Rehabil., 17: 19-28, 2007.

19- ELBOUHY M.S., ABDELHALIM H.A. and HASHEM A.M.: "Effect of respiratory muscles training in weaning of mechanically ventilated COPD patients". Egyptian Journal of Chest Diseases and Tuberculosis, 63: 679-87, 2014.

\section{تآثير تلديبات عضلات الشهيق على جودة الحياة فى مرضى فشل القلب المزيق على جودة}

$$
\text { الهدف: آجريت هذه الرسالة لدراسة تآثير تدريبات عضلات الشهيق على جودة الصياة فى مرضى فثل القلب المزمن. }
$$

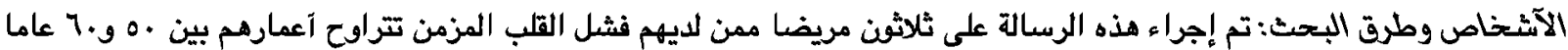

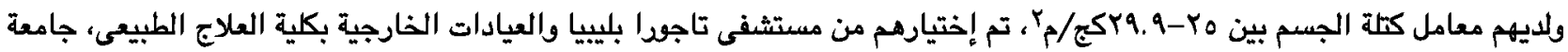

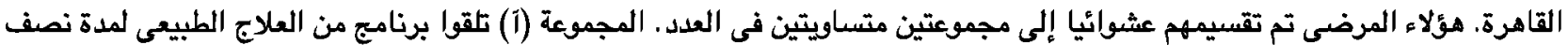

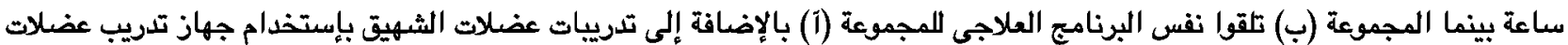

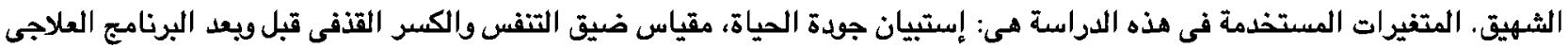

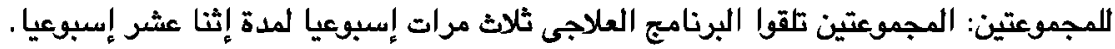

النتائج: أظهرث النتائج وجود فروق ذات دلالة إحصائية لجميع المتفيرات بعد مرد إثنا عشر إسبوعيا متالية المجموعتين (آ وب) وتصسن

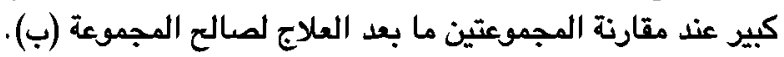

الإستتاج:مع وجود العوائق فى هذه الدراسة لكن يمكن تلخيصها كالآتى: جهاز تدريب عضلات الثهيق يعمل على تقوية عضلات التنفس

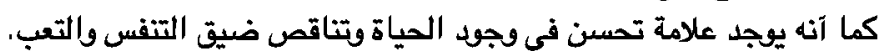

